\title{
A FORMAÇÃO DE PROFESSORES NO BRASIL NO CONTEXTO DA EDUCAÇÃO ESPECIAL
}

\author{
Adriana Martins Silva ${ }^{1}$ \\ Rosane Domingues Lameiro
}

RESUMO: Este trabalho tem como objetivo analisar a formação de professores no Brasil desde os primórdios, as bases legais, as características específicas no contexto da educação especial e os requisitos para uma educação inclusiva. A educação regular como princípio de educação orientada para a inclusão, requer profissionais que atuem com princípios legais e assertividade em suas práticas educativas, realizando ajustes necessários e oportunizando a todos uma educação de qualidade acessível. A formação dos profissionais é a maior ferramenta para permitir uma educação de qualidade e, especialmente, para garantir o apoio adequado aos atendimentos específicos destinados às crianças com deficiência. Com base nas normas legais e instrumentos metodológicos, levantaremos questões relacionadas ao currículo dos profissionais que estão à frente da educação especial, seus marcos legais, características que marcaram a educação especial no Brasil, a primeira formação profissional na área, fundamentos históricos e bases conceituais baseadas em práticas disseminadas nos princípios da Declaração de Salamanca.

Palavras-chave: Formação. Educação. Profissionais.

ABSTRACT: This study aims to analyze teacher education in Brazil from the earliest stages, the legal bases, the specific characteristics in the context of special education and the requirements for an inclusive education. Regular education as a principle of inclusionoriented education requires professionals who act with legal principles and assertiveness in their educational practices, making necessary adjustments and giving everyone an education of accessible quality. Training of professionals is the greatest tool to enable quality education and, in particular, to ensure adequate support for specific care for children with disabilities. Based on legal norms and methodological instruments, we will raise issues related to the curriculum of the professionals who are at the forefront of special education, its legal frameworks, characteristics that marked the special education in Brazil, the first professional training in the area, historical foundations and conceptual bases based in practices disseminated in the principles of the Declaration of Salamanca.

Key words: Formation. Education. Professiona.

\footnotetext{
I Pós -graduanda do Curso de Especialização em Educação Especial - Deficiência Intelectual, UNIJALES, Jales-SP, Email: adrianaconselhoro@gmail.com

${ }^{2}$ Pós -graduanda do Curso de Especialização em Educação Especial - Deficiência Intelectual, UNIJALES, Jales-SP, Email: rosane.domingueso6@bol.com.br
} 


\section{INTRODUÇÃO}

Por meio de reflexões e análises este artigo busca desde as primeiras formações de professores, os marcos na história da educação, contribuindo com dados e informações para apontamento de questões importantes sobre a formação, a importância do professor se dispor em realizar de forma continuada sua formação levantando pontos significativos nos aspectos mais atuais da formação de docentes com atuação na educação especial.

Sabemos que toda a educação brasileira por anos até os dias atuais sofrera mudanças consideráveis, houveram grandes avanços que contribuíram no âmbito da Educação Especial e momentos tempestivos que também marcaram a história da Educação.

Outro ponto que merece atenção são as políticas da educação especial que se reformulou trazendo mudanças estruturais e conceituais, contemplaremos aqui também alguns movimentos políticos que marcaram o período de 2001 até os dias atuais.

Considerando os aspectos legais que subsidiam a atuação dos professores e também os diferentes olhares sobre a educação especial partindo dos professores da sala comum ao professor especializado, qual a aceitação da sociedade em termos de inclusão? Enquanto professores, formamos para uma sociedade justa com condições para que o aluno com deficiência seja incluído e com chances de progredir? Através dessa pesquisa espera-se que possamos contribuir com dados que mostrem a nossa realidade atual experimentada por professores no Brasil em diferentes regiões, pois o nosso país se mostra cheio de diversidades regionais que também comportam de formas diferentes a educação no nosso país.

\section{PRIMEIRA FORMAÇÃO DE PROFESSORES NO BRASIL}

As primeiras formações de professores no Brasil surgiram com a necessidade de organizar a sociedade em nível de instrução logo após ter sido declarada independência do Brasil em i827, quando surgiu as escolas de primeiras letras através da lei de is de Outubro de 1827 , nesta lei podemos verificar que o ensino se praticava mutuamente através do método Lancaster citado no Art. $15^{\circ}$ da Lei de 15 de Outubro "Estas escolas serão regidas pelos estatutos atuais no que se não opuserem á presente lei; os castigos serão os praticados pelo método de Lancaster”. (BRASIL, 2018), assim surge o primeiro método de ensino. 
educacional de castigo físico deveria acabar, instituindo uma nova forma de pensar a disciplina escolar. (MENEZES, 200I, s/p.)

Como na época haviam poucos professores a necessidade que outros alunos ensinassem os grupos era grande, mesmo sendo um método que supria as necessidades da época ainda era algo sem muito preparo.

Surge então as primeiras escolas normal, seguindo modelo Europeu por volta dos anos de i835, fundada em Niterói - RJ escola voltada para formação de professores, este movimento também foi aderido por outras cidades que necessitavam de completar o quadro de professores e foi por muito tempo a maior instituição de ensino para a formação de professores.

Segundo o autor com tantas reformulações e mudanças na tentativa de aperfeiçoamento do modelo de ensino a escola normal findou-se por volta de 1971 quando se institui pela Lei de Diretrizes e Bases a habilitação mínima e específica do magistério, sendo organizada em duas modalidades: básica que habilitava o professor lecionar até a $4^{\underline{a}}$ série, e o outro sendo habilitado para lecionar da $6^{\underline{a}}$ série ao Io grau, currículo este que era válido por todo território nacional.

Mesmo com estes avanços na educação o currículo do professor era muito precário e este fracasso fez com que o governo optasse por um novo projeto com o surgimento de Centro de Formação e Aperfeiçoamento do Magistério (CEFAM) lançado em 1982, este projeto tinha o intuito de reformula e dar condições adequadas para a formação dos profissionais. (SAVIANE, 2008). Como o projeto era restrito houve então a necessidade de instituir o curso de nível superior em pedagogia e acompanhando essas mudanças (LDB) também passa por novas reformulações no ano de 1996, evidenciando a exigência de curso superior para a atuação do docente observada na Lei 9394/96.

\footnotetext{
Art. 62. A formação de docentes para atuar na educação básica far-se-á em nível superior, em curso de licenciatura, de graduação plena, em universidades e institutos superiores de educação, admitida, como formação mínima para o exercício do magistério na educação infantil e nas quatro primeiras séries do ensino fundamental, a oferecida em nível médio na modalidade Normal. (BRASIL, 1996).
}

A educação brasileira a partir de então obteve avanços significativos sempre na busca do oferecimento de qualidade de ensino e garantias de melhorias aos profissionais atuantes, e junto a educação básica nasce a necessidade de incluir "Uma ruptura de base em sua estrutura organizacional, como propõe a inclusão, é uma saída para que a escola possa 
fluir, novamente, espalhando sua ação formadora por todos os que dela participam." (MANTOAN, 2003, p.I2).

\section{PROFESSORES ESPECIALISTAS NA PERSPECTIVA INCLUSIVA}

A educação especial surge no Brasil após passar pelo momento de exclusão, onde as pessoas com deficiências eram segregadas, mantidas longe do convívio social e colocadas à margem da sociedade, o seu surgimento aparece com um conceito de assistencialismo, com a chamada roda dos expostos.

\footnotetext{
De forma cilíndrica e com uma divisória no meio, esse dispositivo era fixado no muro ou na janela da instituição. No tabuleiro inferior da parte externa, o expositor colocava a criança que enjeitava, girava a Roda e puxava um cordão com uma sineta para avisar à vigilante - ou Rodeira - que um bebê acabara de ser abandonado, retirando-se furtivamente do local, sem ser reconhecido. (MARCILIO, 1998, p.107).
}

Sob acolhida as instituições cuidavam dessas crianças e ofereciam asilo, mas ao mesmo tempo segregava, esse contexto acabou perdendo força com as mudanças no sistema econômico, entrando no período de integração, deixando de lado o assistencialismo e promovendo por meio institucional a integração e o convívio em sociedade. "Podemos dizer que a fase de integração se fundamentava no fato de que a criança deveria ser educada até o limite de sua capacidade (MIRANDA, 2003), quando aplicado os métodos de educabilidade esperava-se por cura da deficiência através da educação, aplicando-se métodos e sustentados por essa crença surge então as primeiras instituições para crianças com deficiência.

O Maior marco da história da educação especial no Brasil foi a fundação do (Instituto dos meninos cegos) hoje conhecido como instituto Benjamin Constant fundado em I854, e em I857 o Instituto de surdos e mudos, em seguida por volta de 1950 expandia-se a atenção às classes especiais junto as escolas regulares, é após este período de integração que levantaram-se algumas questões sobre esse paradigma, se seria suficiente promover apenas a integração e ser ainda mantidos de forma segregada?

Com isso a Educação especial abre olhares para a inclusão objetivando dar acesso, garantias de qualidade de ensino e meios para que vivam em sociedade de forma ajustada e suficiente para que leve uma vida com autonomia.

"A inclusão implica uma mudança de perspectiva educacional, pois não atinge apenas alunos com deficiência e os que apresentam dificuldades de aprender, mas todos os 
demais, para que obtenham sucesso na corrente educativa geral". (MANTOAN, 2003, p.25).

Existe a grande necessidade de professores capacitados e de políticas públicas que de suporte adequado para que a educação inclusiva aconteça de forma efetiva, esses dois pontos são os principais na educação especial, é o desafio do professor trabalhar para a inclusão e também a desconstrução histórica e cultural, pela qual passamos de segregação e salas homogêneas. Muitas vezes o despreparo está à frente da atuação, "grandes obstáculos são prontamente apresentados, incluindo a falta de preparação e experiência apropriadas, falta de recursos, de tempo e dinheiro, inadequação dos prédios e falta de apoio da alta administração". (MITTLER, 20oI, p.27).

A Declaração de Salamanca foi um dos documentos norteadores da educação Especial, apresenta um ideal de educação que todos nós gostaríamos de conquistar nos dias atuais, sendo o respeito mútuo às diferenças, as individualidades, das habilidades de cada indivíduo reconhecendo cada ser na sua singularidade. Escrita após sessão plenária da conferência em 1994, podemos perceber que a partir de então as políticas públicas vem se reformulando para que seja possível cada vez mais obter conquistas no âmbito da educação especial na perspectiva inclusiva.

Preparação apropriada de todos os educadores constitui-se um fator chave na promoção de progresso no sentido do estabelecimento de escolas inclusivas. As seguintes ações poderiam ser tomadas. Além disso, a importância do recrutamento de professores que possam servir como modelo para crianças portadoras de deficiências torna-se cada vez mais reconhecida. (BRASIL, 1994).

O que consiste na preocupação do professor, muitas vezes é a prática que precisa ser vivenciada de forma flexível e organizada para cada situação, e durante os anos de estudos na faculdade aprendemos a lidar somente com a teórica, visto que também nas licenciaturas o preparo para receber o aluno com deficiências é escasso, se tornando incoerente com a realidade que vivenciamos, por isso a busca por uma especialização se torna algo importante até mesmo pra poder incluir os alunos que estão na rede regular, a compreensão sobre as deficiências auxilia o trabalho do professor, é claro que não existe método ou técnica especifica, pois há muitas variações, não temos padrões em níveis de deficiência. Mas ainda assim, o aperfeiçoamento sobre o conhecimento na área da deficiência é um caminho que norteia os trabalhos e se une as experiências vivenciadas, pois somente o contato durante as situações de aprendizagens que fornecerá informações 
necessárias para o professor saber quais as melhores formas de planejar as suas práticas (BRASIL, 1994).

O professor precisa planejar e se adaptar de acordo com as potencialidades dos alunos, proporcionar tempos e espaços de aprendizagens, agrupamentos e ser reflexivo perante as suas práticas, para que saiba também lidar com as frustrações e através dos erros retirar experiências para sua própria evolução em beneficio ao seu trabalho.

Dentro da educação especial podemos distinguir quatro tipos de atendimento, as salas de inclusão onde o aluno se encontra na sala de aula regular e passa por atendimentos específicos por equipe multidisciplinar, o AEE (Atendimento Educacional Especializado em sala de recurso), o AEE (Atendimento Educacional Especializado em itinerancia) e o atendimento institucional feito em APAES nos casos mais severos.

Segundo artigo $3^{\circ}$ da Resolução SE 6I o atendimento Pedagógico especializado dar-se à:

Em sala de recursos, definida como ambiente dotado de equipamentos, mobiliários e materiais didáticos, visando ao desenvolvimento de habilidades gerais e/ou especificas, mediante ações de apoio, complementação ou suplementação pedagógica. (BRASIL, 2014).

Resolução SE, 68 Artigo $5^{\mathfrak{o}}$ - Os pedidos de autorização para oferta de Atendimento Educacional Especializado - AEE, sob a forma de Sala de Recursos ou na modalidade itinerante, deverão comprovar a existência de demanda, e ser instruídos com:

I - avaliação pedagógica, realizada por professor especializado, e psicológico do aluno, em caso de deficiência intelectual;

II - laudo médico, no caso de deficiências auditiva/surdez, física, visual, surdo, cegueira, transtorno do espectro autista e deficiência múltipla e múltipla sensorial;

III - avaliação pedagógica realizada por professor especializado, complementada por avaliação psicológica, em casos de altas habilidades ou superdotação;

IV - parecer da equipe de Educação Especial da Diretoria de Ensino. (BRASIL, 2017).

$\mathrm{Na}$ itinerancia o professor desloca até a escola onde o aluno está matriculado, e no atendimento institucional são em instituições de ensino (APAE) que trabalham diferente dos conteúdos convencionais, trabalha-se fortalecendo os laços de vínculos afetivos e suas potencialidades.

O objetivo do atendimento educacional especializado é propiciar condições e liberdade para que o aluno com deficiência mental possa construir a sua inteligência, dentro do quadro de recursos intelectuais que the é disponível, 
tornando-se agente capaz de produzir significado/conhecimento." (MEC/SEESP, 2006).

A educação especial depende de vários fatores para ser efetivada com sucesso, além do professor com a sua atuação baseada nos padrões legais e metodologia, é necessário a articulação entre a equipe escolar e familiares dos alunos.

Podemos dizer que a inclusão impõe quebra de barreiras, superar um sistema tradicional de educação e uma visão conservadora não é missão fácil para profissionais que por muitas vezes estão à frente da educação há vários anos.

\begin{abstract}
A inclusão não prevê a utilização de práticas de ensino escolar específicas para esta ou aquela deficiência e/ ou dificuldade de aprender. Os alunos aprendem nos seus limites e se o ensino for, de fato, de boa qualidade, o professor levará em conta esses limites e explorará convenientemente as possibilidades de cada um. Não se trata de uma aceitação passiva do desempenho escolar, e sim de agirmos com realismo e coerência. (MANTOAN, 2003, p.36).
\end{abstract}

Por isso a grande necessidade de que o professor abrace a causa e lute para que a inclusão de fato aconteça, e uma das melhores formas é investindo fortemente em novos conhecimentos, reformulando conceitos, capacitações para que possa melhor desenvolver suas habilidades e sem dúvida incentivo por parte dos governos que estão à frente das políticas públicas.

\title{
INCLUSÃO
}

A educação inclusiva é uma modalidade que abrange diversas deficiências, sendo elas a deficiência física, intelectual, transtornos globais do desenvolvimento, altas habilidades, superdotação, auditiva e visual, são abordados por todos os níveis educacionais (ensino infantil, fundamental, médio e também o ensino superior). (MANTOAN. 2003).

A inclusão surge quando algumas mudanças passaram a fazer parte do sistema educacional, as salas de educação especiais deram espaços para as salas de recursos, onde o professor especializado faz os atendimentos (AEE) atendimento Educacional Especializado, realiza intervenções necessárias para uma melhoria em aspectos mais específicos dando apoio ao ensino regular, que ele frequenta em contra turno.

Sendo assim a educação especial não foi extinta, ela tornou-se complementar ao ensino regular e deixou de ser excludente, como antes que era uma sala que privava os alunos de ser, conhecer, aprender, conviver e fazer só assim quebrará o paradigma que a educação inclusiva é desnecessária. 
De acordo com a autora Breyer, dentro da inclusão escolar não é somente alunos, professores e funcionário que precisam se adequar, mas também o ambiente que este aluno está inserido, a infra- estrutura, rampas, pisos, placas sinalizadoras, materiais que dão suporte, pois sabemos que o recursos financeiros que as escolas recebem são mínimos. (Breyer, 20II).

Sabemos que não é uma caminhada fácil nem tão rápida, mas que chegamos juntos à algum lugar, quando todos se propõe a trabalhar, a fazer, e principalmente a querer que tudo que está nas legislações através do (ECA), do Plano Nacional da Educação e Constituição Federal faça valer, saindo do papel e fazendo parte de vidas reais.

Diante de tantos desafios para serem discutidos e debatidos são inúmeros, muito ainda tem à ser feito em cidades de todo o Brasil, mas isso não será possível, enquanto as políticas públicas educacionais não se concretizarem no dia a dia e estiverem presente da prática do professor, na formação continuada, remuneração decente e principalmente investimento na qualidade da educação dessa geração que influenciará a outra e transmitirá esse ideário inclusivo, até que, quem saiba um dia, os preconceitos não existam mais.(NIEVOLA, 20II).

Dentro da escola inclusiva encontramos espaços adequados, organização dos ambientes, uma proposta política pedagógica (PPP) que esteja de acordo com ambiente proposto e tecnologias assistivas como: e-books, book reader, Braille lite, capacete com ponteiras, lupa eletrônica, programa dosvox, e além de materiais feitos com reciclagem também que são econômicos e com ótimos resultados.

A inclusão além de ser um dos temas mais falados, será que sabemos responder a questão?

Qual a importância da inclusão nas escolas? Poderíamos responder que a inclusão é um ato que oficializa a garantia de direitos das pessoas, que por simplesmente estarem em condições diferentes, são privadas, limitadas, restringidas por uma sociedade que culturalmente exclui as pessoas denominadas "diferentes", dentro dos padrões que são ditos como "normal".

Oportunizar outras crianças conviverem com as diferenças garantem experiências extraordinária, sem falar que se solidarizam e partir daí criamos princípios fundamentais para criar uma sociedade mais justa.(SANTANA, 20I2) 
Convivendo com as diferenças oportunizamos a chance de crianças crescerem e se tornarem adultos mais resistentes aos preconceitos, serem compreensivas com o próximo, olhar o outro e enxergar suas qualidades, entender e reconhecer que somos dotados de habilidades e também limitações.

O planeta necessita, em todos os sentidos, de compreensão mútua. Considerando a importância da educação para a compreensão, em todos os níveis educativos e em todas as idades, o desenvolvimento da compreensão pede a reforma das mentalidades. (MORIN, 200o, p.I7)

As nossas políticas públicas estão sempre com novas reformulações, mas as atitudes também precisam passar por reformulação, as mentes humanas necessitam se readaptar e se conscientizar das diversidades que o mundo hoje suporta para garantir o que já é de direito e incluir a todos, oportunizando avanços para que vivam com suas liberdades, suas criatividades e transcendam as suas limitações.

\begin{abstract}
A inclusão é produto de uma educação plural, democrática e transgressora. Ela provoca uma crise escolar, ou melhor, uma crise de identidade institucional, que, por sua vez, abala a identidade dos professores e faz com que seja ressignificada a identidade do aluno. $\mathrm{O}$ aluno da escola inclusiva é outro sujeito, que não tem uma identidade fixada em modelos ideais, permanentes, essenciais." (MANTOAN, 2003,p.20).
\end{abstract}

Segundo a autora a luta é contra uma resistência que ainda contempla parte da sociedade, é compreensível pois é um produto criado historicamente, mas o nosso sistema educacional evolui tão rapidamente, e esse assunto ainda continua sendo um entrave, incluir exige compreender as diferenças e não simplesmente passar para o especialista como uma forma de não se responsabilizar pela aprendizagem da pessoa com deficiência.

A deficiência é vista como algo indelével, e isso chama mais atenção pois mantemos nossos olhares tão voltados pra esse fato de tal modo que a fixamos permanentemente em suas vidas e não ultrapassa-se esse limite que está mais na barreia imposta que na própria deficiência.

\title{
CONSIDERAÇÕES FINAIS
}

Através deste artigo foi possível verificar por pesquisas e reflexões, que a busca por conhecimento na formação do currículo do professor, ainda é uma das maiores ferramentas no âmbito educacional para que se possa promover a inclusão. 
Quando falamos sobre a abordagem da formação do professor na educação especial, podemos julgar que as experiências escolares fazem parte de um processo norteador das práticas, das elaborações, planejamento e do produto final do conhecimento.

Se formamos professores com todas essas características, com certeza eles terão uma atuação relevante, respeitando as diversidades de todos seus alunos, seja deficiente ou não, cor, raça, etnia ou cultura diferente. Formação continuada faz parte desse processo também e deve ser compromisso dos sistemas de ensino, que comprometidos com a qualidade dos mesmos, é fundamental ter um olhar diferente sobre os discentes para conhecer as especificidades de cada um.

Não cabe somente ao professor a responsabilidade da inclusão, a escola precisa também estar envolvida, familiares e alunos. Mesmo quando falamos em professores especialistas, precisamos refletir que o mesmo também tem erros e acertos, mas que a partir dos erros faça-se uso para melhor reformular, readaptar e organizar suas práticas.

A função de educar para a inclusão começa tirando às vendas dos olhos de todos os que pensam que a educação especial não cabe a ele, não se responsabilizando, deixando o fardo pro outro, é mais fácil quando não temos obstáculos à nossa frente, mas esquecemos que com todas as barreiras e obstáculos é que se obtêm ganhos, e o maior ganho é poder garantir a qualquer pessoa os seus direitos,

O ideal ainda não é coerente com o real e isso está visível a todos quando podemos encontrar documentos legais que na prática não funcionam, além da falta de manutenção e suporte no sistema educacional.

Por meio de uma prática adequada, que compreenda e valorize a sua clientela, é possível proporcionar um acolhimento evitando-se o sofrimento dos alunos frente às dificuldades de compreensão das atividades propostas e atendê-los.

A educação precisa ser pensada como um ato de ferramenta de formação de cidadãos, se o professor faz essa situação ser significativa para o aluno, e deixa marcas de bons exemplos na educação especial também é possível, o que precisa é de ajustes proporcionais aos alunos que recebemos.

Por tanto chegamos ao fim deste artigo com um pensamento mais aberto e reflexivo sobre a proposta da inclusão, reconhecendo ela como parte da formação de qualquer professor, tanto o especialista quanto o professor da rede regular precisara se 
adequar, e entender que este modelo atual está muito distante do tradicionalismo ditado por anos em nossas escolas.

O profissional que busca o conhecimento ele nunca é arcaico, está sempre se renovando e produzindo ofertas novas de práticas diferenciadas.

\section{REFERÊNCIAS}

BRASIL. Declaração de Salamanca Sobre Princípios, Políticas e Práticas na Área das Necessidades Educativas Especiais. Brasília: UNESCO, ı994;

BRASIL. Resolução SE 68, Dispõe sobre o atendimento educacional aos alunos, públicoalvo da Educação Especial, do Decreto 57.141, deı8/7/ı1 I2 de Dez. 2017.

BRASIL. Lei de Diretrizes e Bases da educação, 1976.

BRASIL. Lei de Diretrizes e Bases da Educação. Lei 9.394, de 20 de Dezembro de 1996. Diário Oficial da União, Brasília, 1996.

BRASIL. Resolução SE 68, Dispõe sobre o atendimento educacional aos alunos, públicoalvo da Educação Especial, do Decreto 57.141, deı/7/11 I2 de Dez. 2017.

BRASIL, COLEÇÃO DE LEIS DO IMPÉRIO DO BRASIL - ı827, Página 7I Vol. I pt. I (Publicação Original). Acesso em: o8 de Dez. 2018, disponível em: <http://www2.camara.leg.br/legin/fed/lei_sn/I824-I899/lei-38398-15-outubro-1827-566692publicacaooriginal-90222-pl.html $>$. Acesso em o6 Dez. 2018.

BREYER.P.A. Educação Inclusiva, Transpondo barreiras para uma inclusão educacional, Universidade de Brasília (UnB) Brasília, 2oII.

BERTOLDO, A.A.História, deficiência e educação especial. Miranda FACED/Universidade Federal de Uberlândia, Uberlandia MG, 2003

CUNHA, R.C.O.B; PRADO, G.V.T. Formação centrada na escola, Desenvolvimento Pessoal e Profissional de Professores. Revista de Educação PUC-Campinas, Campinas, n.28, p.ior-III, jan./jun., 2010.

MEC/SEESP. Educação Inclusiva Atendimento Educacional Especializado para a Deficiência Mental. Brasília-2006, Disponível em: $\langle$ http://portal.mec.gov.br/seesp/arquivos/pdf/defmental.pdf〉. Acesso em o8 Dez.2018.

MANTOAN, M.T.E. Inclusão escolar: O que é? Por quê? Como fazer? São Paulo: Moderna, 2003.

MARCÍLIO, M. L. História social da criança abandonada. São Paulo: Hucitec, 1998.

MENEZES, E.T SANTOS, T.H. Verbete método lancasteriano. Dicionário Interativo da Educação Brasileira - Educabrasil. São Paulo: Midiamix, 200r.Disponível em: 〈http://www.educabrasil.com.br/metodo-lancasteriano/>. Acesso em: 12 de dez. 2018 
MITTLER, P. Rumo à inclusão. Proposições. V. 12. N. 2-3 (35-36). jul.- nov. 200 I

MORIN, E. Os sete saberes necessários à educação do futuro. 2. ed. São Paulo : Cortez, Brasília, DF : UNESCO, 2000.

NIEVOLA, C. R. Políticas públicas da educação e gestão democrática e participativa na escola. a Universidade Tecnológica Federal do Paraná (campus Curitiba). Curitiba. PR. 2011.

Disponívelem:http://repositorio.roca.utfpr.edu.br/jspui/bitstream/I/II43/I/CT_GPM_I_2 oII_I8.PDF. Acesso: 1o. Dez. 2018.

SAVIANE, D. Formação de professores: aspectos históricos e teóricos do problema no contexto brasileiro, Universidade Estadual de Campinas, Faculdade de Educação- SP, 2008.

SANTANA, D.M. Sociedade, Estado e Direito: Os princípios da democracia. Faculdade de Ciências Humanas e Sociais - AGES, 2012. Disponível em:< https://jus.com.br/artigos/48688/sociedade-estado-e-direito-os-principios-dademocracia $>$. Acesso: 09. Dez. 2018. 